\title{
Tailored management approach for late presenters and critically sick children with congenital heart disease
}

\author{
Milad El-Segaier ${ }^{1,2}$ and Mohammed Omar Galal ${ }^{3 *}$ \\ ${ }^{1}$ Prince Salman Heart Center, Riyadh \\ ${ }^{2}$ Skane University Hospital, Lund, Sweden \\ ${ }^{3}$ King Faisal Specialist Hospital \& RC, Jeddah, Saudi Arabia
}

\begin{abstract}
Background and objectives: Pre-conditioning before cardiac surgery in critically sick children is often needed. We report our experience using tailored management approach in these patients.

Methods and patients: The charts of patients with congenital heart disease CHD who were judged to have high operative risk were reviewed. Included were patients with: large systemic to pulmonary shunt and ventilation for longer than 2 months, significant systemic to pulmonary shunts at multiple levels combined with malnutrition or recent infection, severely impaired myocardial function needing inotropic support, recent respiratory syncytial virus (RSV) infection, severe malnutrition (body weight $<5^{\text {th }}$ centile), and critically sick patients during early postoperative course. Excluded were patients with: significant systemic to pulmonary shunts who presented early, with minor growth retardation, and without recent active infection.

Result: Six patients were included. The median age was 13 months (2-48months) and median weight was $4.6 \mathrm{~kg}(2.3-12.6 \mathrm{~kg})$. Two patients had multiple systemic to pulmonary shunts and ventilator dependency. One with huge VSD presented at four years of age. Another with low body weight, large VSD and impaired myocardial function. Two more with early postoperative complications and ventilator dependency.

In the first category, staged approach was essential. This was done by transcatheter closure of the PDA, followed by pulmonary artery banding. This approach lead to extubation. After improving nutritional status, total correction was done. The patient who presented at four years of age underwent banding of PA, later surgical repair of VSD. Because of long postoperative ICU stay, he needed percutaneous closure of his residual VSD and then discharged. The patient with large muscular VSD and impaired myocardial function underwent percutaneous VSD closure with good result despite low weight (4.2 kg). The last two patients; one needed balloon dilation of residual coarctation, the other because of severe obstruction to his bilateral Glenn anastomosis, underwent stenting of these stenosis. Both had good result.
\end{abstract}

Conclusion: In severely sick children and late presenter with multiple shunts, a tailored management including therapeutic catheterization and supportive measures are essential before cardiac surgery. Catheterization and possible intervention should be considered early during postoperative phase in severely sick patients.

\section{Introduction}

Introduction of interventional catheterization opened new venues in the treatment of patients with congenital heart disease [1]. Before this era, very sick or neglected patients were either denied surgery or underwent high risk procedures. With time as the concept of hybrid procedures find acceptance in the management strategies for some patients with congenital heart disease (CHD) [2], we recognized that some patients, who present late for different reasons, might benefit from similar staged or tailored procedures.

These patients according to our understanding are the product of less than perfect primary and secondary health care systems. We believe that with improvement of these necessary systems in our area, this kind of patients will get less with time [3].

It is our aim to report cases with CHD which were referred to our institute for surgical treatment. However, at their arrival it showed that they are either late presenter or some of them so critically sick and have not been optimally treated. They were marasmic, with chronic lung disease, and some of them ventilator dependent for long times. We chose to treat these patients starting with optimizing medical treatment, partial treatment through intervention cardiac catheterisation, general and cardiac rehabilitation and finally at a later stage proceeding with bypass cardiac surgery. We believe that this approach had minimized the expected high risk and lead to better final result.

\section{Methods}

The charts of all patients who were referred to our institution with CHD necessitating surgical correction were reviewed in this retrospective study. Included were patients who were assumed and judged to have high risk if they would have been sent for surgery without adequate general and cardiac preparations.

\section{Inclusion criteria}

Patients with large systemic to pulmonary shunt and on the ventilator for longer than two months, patients who were judged to have

Correspondence to: Milad El-Segaier, King Fahad Medical City, PSHC, Riyadh, E-mail: mail4milad@gmail.com

Key words: tailored management approach, congenital heart disease, interventional procedures, and late presenter

Received: September 22, 2017; Accepted: October 25, 2017; Published: October 28,2017 
a sepsis and remain ventilator dependent, patients with recent (within 3 weeks). Respiratory Syncytial Virus (RSV) infection, patients who arrive in marasmic condition (with body weight and height far below the $5^{\text {th }}$ centile for their age). Patients with large systemic to pulmonary shunts at multiple levels combined with moderate malnutrition or recent viral infection, patients with significant impaired myocardial function needing inotropic support and patients who remained critically sick at early postoperative course.

\section{Exclusion criteria}

Excluded were patient with large systemic to pulmonary shunts but were sent in timely fashion (less than 8 months of age), patient with just minor growth retardation, and patients with no active bacterial or recent viral infections.

The study period was from January 2010 until December 2011. The patient's files were reviewed for demographic and clinical data, including echocardiographic findings, pre and post treatment, cardiac catheterisation reports and the angiographic films. The follow-up study period ended December 2012. Follow-up time was a median of 14 months (range3 to 35 months). The study was approved by the Institutional Regulatory board (IRB) at the King Fahad Medical City, Riyadh, Saudi Arabia. Because the study was retrospective, the committee waived the need for parental consent.

\section{Patient population}

We identified six patients (three boys, and three girls) who qualified for inclusion. The median age at referral was 13 months, mean 16 months (range: 2 to 48 months). Their median weight was $4.6 \mathrm{~kg}$, mean of $6.6 \mathrm{~kg}$ (range, $2.3-12.6 \mathrm{~kg}$ ).

The catheterization procedure was performed by two experienced paediatric cardiac interventionalist (MS, MOG), under general anaesthesia, utilizing echocardiography (transesophageal; TEE or transthoracic; TTE) guidance if needed and using a monoplane cardiac catheterisation C-arm. A summary of patient's clinical presentation, their cardiac diagnoses the surgical and interventional procedure and the final outcome are presented in table 1.

\section{Cases and result}

\section{Case 1}

At 13 months of age this girl was referred to us with the diagnosis of multiple ventricular septal defect (VSD), large patent ductus arteriosus (PDA) and possible mitral valve stenosis. Early in her life, at the age of 2 months, she suffered of severe respiratory infection (possible RSV), and admitted to Pediatric Intensive Care Unit (PICU) at the regional hospital. Due to respiratory insufficiency she was intubated and ventilated. Later, because of long standing ventilator dependency, she had tracheostomy. When she was admitted at our institution after 11 months of mechanical ventilation, she was in severe failure to thrive (body weight was $4.6 \mathrm{~kg}\left(<5^{\text {th }}\right.$ centile), had a tracheostomy and was still ventilator dependent. Chest $\mathrm{x}$-ray showed cardiomegaly and sign of increased pulmonary blood flow. No sign of parenchymal lung disease. Echocardiography (Echo) confirmed the above diagnosis (namely multiple VSDs and large PDA). However, the mitral valve was of normal dimension and no sign of stenosis. The left atrium and left ventricle were volume overloaded which indicated large transpulmonary flow and possible low pulmonary vascular resistance. We chose to catheterize her, evaluate her pulmonary artery pressure and in the same session close her PDA if no hemodynamic contraindication.

\section{Procedure}

Under general anaesthesia the femoral vein and artery were accessed. Through the venous access the pulmonary artery pressure

Table 1. Summary of the presented cases

\begin{tabular}{|c|c|c|c|c|c|}
\hline No. & $\begin{array}{l}\text { Age, } \\
\text { (weight), } \\
\text { [Gender] }\end{array}$ & Diagnosis & $\begin{array}{l}\text { Clinical Picture and associated } \\
\text { conditions }\end{array}$ & Procedures & Outcome \\
\hline 1 & $\begin{array}{l}13 \mathrm{M}(4.6 \\
\mathrm{kg}),[\mathrm{F}]\end{array}$ & Multiple VSDs \& large PDA & $\begin{array}{l}\text { Marasmic, tracheostomy, } \\
\text { ventilator dependent for } 11 \\
\text { months }\end{array}$ & $\begin{array}{l}\text { 1- PDA device closure } \\
\text { 2- PAB } \\
\text { 3- Surgical VSD closure }\end{array}$ & $\begin{array}{l}\text { Support with CPAP one week after first } \\
\text { intervention, stop respiratory support after } \\
\text { PAB. Discharged with nutritunial support. } \\
\text { Final result VSD closed and catching up with } \\
\text { her psychomotoric and somatic development }\end{array}$ \\
\hline 2 & $\begin{array}{l}3 \mathrm{M} \\
(3.1 \mathrm{~kg}),[\mathrm{F}]\end{array}$ & Unbalanced AVSD \& large PDA & $\begin{array}{l}\text { FFT, ventilator dependent ( } 2 \\
\text { mons), Down's syndrome, }\end{array}$ & $\begin{array}{l}\text { 1- PDA device closure } \\
\text { 2- PAB }\end{array}$ & $\begin{array}{l}\text { Improved gradually after the two consecutive } \\
\text { stages. Awaiting final procedure. }\end{array}$ \\
\hline 3 & $\begin{array}{l}4 \mathrm{Y}, \\
(12.6 \mathrm{~kg}),[\mathrm{M}]\end{array}$ & $\begin{array}{l}\text { Congenital complete AV block and } \\
\text { large inlet VSD }\end{array}$ & $\begin{array}{l}\text { NYHA IV, heavy anti-failure } \\
\text { medications, FFT }\end{array}$ & $\begin{array}{l}\text { 3- Surgical VSD closure } \\
\text { 2- Residual VSD device closure and } \\
\text { insertion of pacemaker lead } \\
\text { 3- Change pacemaker device from VVI } \\
\text { to DDD mode } \\
\text { 4- Second residual VSD device closure }\end{array}$ & $\begin{array}{l}\text { After surgery stayed oxygen dependency and } \\
\text { ICU care until residual VSD device closure } \\
\text { and DDD pacemaker. After additional VSD } \\
\text { device, further clinical improvement }\end{array}$ \\
\hline 4 & $\begin{array}{l}4 \mathrm{M}, \\
(4.2 \mathrm{~kg}),[\mathrm{F}]\end{array}$ & $\begin{array}{l}\text { Moderate large ASD, large } \\
\text { midmuscular VSD }(8.5 \mathrm{~mm})\end{array}$ & $\begin{array}{l}\text { Severe CHF, depressed } \\
\text { myocardial function (SF 25\%) }\end{array}$ & Muscular VSD device closure & $\begin{array}{l}\text { Dramatic clinical improvement after VSD } \\
\text { device closure }\end{array}$ \\
\hline 5 & $\begin{array}{l}45 \mathrm{D}, \\
(2.3 \mathrm{~kg}),[\mathrm{F}]\end{array}$ & $\begin{array}{l}\text { Co A, aortic arch hypoplasia and large } \\
\text { VSD }\end{array}$ & $\begin{array}{l}\text { Small body weight, ventilator } \\
\text { dependent, multiple organ failure }\end{array}$ & $\begin{array}{l}\text { 1- Surgical repair of Co A and arch } \\
\text { reconstruction } \\
2 \text { - balloon dilation of residual Co A } \\
\text { twice } \\
\text { 3- PAB }\end{array}$ & $\begin{array}{l}\text { Resolution of life threatening condition after } \\
\text { first balloon dilation. Further drop in gradient } \\
\text { after second balloon anastomosis, but needed } \\
\text { PAB }\end{array}$ \\
\hline 6 & $\begin{array}{l}14 \mathrm{M} \\
(9.3 \mathrm{~kg}),[\mathrm{M}]\end{array}$ & $\begin{array}{l}\text { Situs ambiguous, SA, SV, TGA, } \\
\text { bilateral SVC, interrupted IVC with } \\
\text { hemiazygos continuation to the left } \\
\text { SVC and hypoplasia of both PA } \\
\text { branches }\end{array}$ & $\begin{array}{l}\text { Severe cyanosis after Glenn } \\
\text { operation ( } 45 \% \text { Saturation }) \text {, } \\
\text { needed ICU care }\end{array}$ & $\begin{array}{l}\text { 1- Modified BT shunt } \\
\text { 2- Bilateral Glenn anastomosis } \\
\text { 3- Balloon dilation of right Glenn } \\
\text { anastomosis } \\
\text { 4- Stenting of left Glenn anastomosis } \\
\text { and LPA }\end{array}$ & $\begin{array}{l}\text { Marked clinical improvement after major } \\
\text { interventions. Waiting for further surgery. }\end{array}$ \\
\hline
\end{tabular}

$\mathrm{VSD}=$ ventricular septal defect, PDA = Patent Ductus Arteriosus, PAB = Pulmonary artery band, CPAP $=$ Continuous Positive Airway Pressure, AVSD $=$ Atrio-Ventricular Septal Defect FTT $=$ Failure to Thrive, ICU = Intensive Care Unit, ASD = Atrial Septal Defect, CHF = Congestive heart failure, Co A = coarctation of the aorta, SA = Single Atrium, SV = Single Ventricle, $\mathrm{TGA}=$ Transposition of Great Arteries, SVC = Superior Vena Cava, IVC = Inferior Vena Cava, PA = Pulmonary Artery, LPA = Left Pulmonary Artery. 
was measured $(63 / 35$, mean $42 \mathrm{mmHg})$ and the ratio of systemic to pulmonary shunt (Qp:Qs) was 2.2:1. Through the arterial access the aortic pressure measurement was 64/38, mean $46 \mathrm{mmHg}$. Left ventricle (LV) angiography showed one large perimembraneous VSD and three other small muscular VSDs. The aortography, at distal aortic arch showed a large PDA $(3 \times 4.6 \mathrm{~mm})$. With these results (pressures and Qp:Qs), we decide to close the PDA with a 4 x 6 Amplatzer PDA-I occlude (AGA Medical Co, Golden Valley, MN, USA). The device was deployed through the usual delivery system with no complication. A control aortography then showed no residual shunt and the device in good position. The pulmonary artery pressure at the end catheterization was $68 / 33$, mean $51 \mathrm{mmHg}$ while the systemic pressure was $76 / 43$, mean $59 \mathrm{mmHg}$ and the Qp:Qs was 1.8:1.

Six days after PDA closure the girl could be extubated to Continuous Positive Airway Pressure (CPAP). As we were not able within 3 weeks to wean her off the CPAP, and because of her fragile general condition, we choose to operate her with pulmonary artery band (PAB), an adjustable band (Flow Watch), instead of closing her ventricular septal defects. Within few days after PAB she could be weaned off her tracheostomy. Three weeks later she could be discharged home, continued on her medications and intensive nutritional support. On follow up visits the adjustable band was gradually tightened. Clinically she improved and started to gain weight. Later (after eight months) she was operated with surgical closure of her VSD and de-banding. On follow-up gradually, she gained weight and caught up her motor and psychological developments. At 30 months of age, she is clinically doing fine, her body weight of $12 \mathrm{~kg}$ and her neurological and psychological developments were normal.

\section{Case 2}

This girl was born with Down's syndrome and diagnosed early to have unbalanced atrio-ventricular septal defect (AVSD) and large PDA. At one and half month of age she had weight of $3.1 \mathrm{~kg}$, got respiratory infection which lead her to PICU admission and then became ventilator dependent for two months. We concluded that she was not qualified for bi-ventricular repair (combination of unbalanced AVSD and Down's syndrome gives poor prognosis for uni-ventricular repair). Therefore, we elected to take her for cardiac catheterisation and close her PDA, hoping she will get off the ventilator.

\section{Procedure}

Under general anaesthesia the femoral vein and artery were accessed. The pulmonary artery pressure was $61 / 22$, mean $42 \mathrm{mmHg}$, the aortic pressure was 70/31, mean $48 \mathrm{mmHg}$ and the Qp:Qs was 1.8:1.The aortography showed a large, horizontal and tubular PDA (narrowest diameter $3.5 \mathrm{~mm}$, aortic diameter $4.5 \mathrm{~mm}$ and length was $11 \mathrm{~mm}$ ). Due to the PDA morphology, we decided to close the PDA with an $8 \mathrm{~mm}$ Amplatzer vascular plug-II device (AGA Medical Co, Golden Valley, MN, USA). Through a 5 Fr MPA-I catheter the device was deployed into the PDA and then released. A control aortography showed only mild residual leak through the plug which has good position.

The girl then could by extubated after five days and stayed on CPAP through face mask. Her X-ray continued to be congested, therefore after two weeks she was operated with $\mathrm{PAB}$, adjustable band (Flow Watch). On follow-up, at 22 months of age she is clinically doing fine, has saturation of $87 \%$ and body weight of $11 \mathrm{~kg}$. She is waiting for cardiac catheterisation before planned final surgical operation, possibly with bidirectional cavo-pulmonary anastomosis as one and half ventricular repair.

\section{Case 3}

This boy came to our emergency department at the age of four years with respiratory infection. He is a case of congenital complete atrio-ventricular block and large inlet VSD. Previously, at another institute he had cardiac surgery through median sternotomy at the age of eight months with PAB and pacemaker (VVI system) implantation. He lost follow-up at that institute for three years. He was admitted to our institute and treated for his respiratory infection. Clinically he had tachypnea, saturation $93 \%$ and weight $12.6 \mathrm{~kg}$. His heart sounds were normal and had ejection systolic murmur (grade IV/VI) at the left upper sternal border. His liver was palpable $4 \mathrm{~cm}$ below right costal margin. He was in NYHA functional class was IV/IV. The chest X-ray showed increased pulmonary vascularity and cardiomegaly. By Echo he had large inlet VSD and PAB at middle of main pulmonary artery. The Doppler gradient across the band was $40 \mathrm{mmHg}$, indicating loose band or high distal pulmonary artery pressure. After treatment of his respiratory infection and with intravenous diuretics he improved clinically but continued to have moderate respiratory distress, tachypnea and moderately large liver. We decided to re-evaluate his pulmonary vascular resistant (PVR)and his response for vasodilator medication (Oxygen and Nitric Oxide). The result of cardiac catheterisation hemodynamic shown in table 2.

With these hemodynamic results (presented in table 2) we concluded the patient operable and he was referred to cardiac surgery. Intraoperatively, unfortunately the child had extensive adhesions resulted from the previous operations which lead to cannulation difficulties and prolongation of the operation time. The VSD was closed by Gortex patch with some interference with the cordea of the tricuspid valve. The $\mathrm{PAB}$ was removed. Intraoperative transesophageal Echo (TEE) showed two residual shunts at superior-posterior edge of the VSD patch and moderate tricuspid valve regurgitation. Doppler gradient estimated the right ventricle pressure to be $45 \mathrm{mmHg}$. The patient was shifted to the PICU on Nitric Oxide (15 ppm). Postoperatively, he developed sepsis leading to multiple organ failure. After adequate treatment, slowly he recovered and could be weaned of mechanical ventilation. However, he continued to be oxygen dependent to keep his saturation above $90 \%$. It was unclear whether he had some degree of increased pulmonary artery (PA) pressure or his residual shunts played some role in his clinical picture. Therefore, we started him on vasodilator medications (Sildenafil and Endotheline-I antagonist). Despite different manoeuvres and changes in management, he remained in critical situation. Echo showed a residual VSD as well as moderate tricuspid regurgitation (TR), the right ventricle (RV) pressure by Doppler assessment approaching $70 \%$ systemic. Our assumption was that his critical situation is due to increase of diastolic RV pressure or increased PA pressure. Thus, we decided to catheterise him for: a) evaluate his hemodynamics, b) possibly close any significant residual VSD, and c) implant an atrial pacemaker lead to replace his VVI pacemaker mode to a DDD mode.

Table 2. The hemodynamic results of the case number 3

\begin{tabular}{|c|c|c|c|c|}
\hline & $\begin{array}{c}\text { MPA pressure } \\
\text { Systolic/ } \\
\text { diastolic, mean }\end{array}$ & $\begin{array}{c}\text { Systemic } \\
\text { pressure }\end{array}$ & MPA saturation & PVRI \\
\hline Baseline & $67 / 22,43$ & $97 / 46 / 65$ & $80 \%$ & 8.6 \\
\hline NO 10 ppm & $70 / 15,40$ & $87 / 50 / 68$ & $90 \%$ & 4.0 \\
\hline FiO2 100\% & $62 / 12,35$ & $77 / 45 / 60$ & $98 \%$ & 2.5 \\
\hline $\begin{array}{c}\text { NO 10 ppm + } \\
\text { FiO2 100\% }\end{array}$ & $63 / 11,33$ & $80 / 48 / 62$ & $98 \%$ & 2.9 \\
\hline
\end{tabular}

Wedge pressure $=6 \mathrm{mmHg}$ and mean right atrial pressure $=3 \mathrm{mmHg}$. MPA $=$ Main Pulmonary Artery. PVRI = Pulmonary Vascular Resistance Index. NO = Nitric Oxide. 
At repeated catheterisation he has: right atrial (RA) pressure of $19 / 17 / 16 \mathrm{mmHg}$, RV pressure of $62 / 11$, RV EDP of $18 \mathrm{mmHg}$, PA pressure of 56/21, mean $36 \mathrm{mmHg}$ and systemic systolic pressure of $70 \mathrm{mmHg}$. The Qp:Qs after repeated sampling was 2.6:1. Therefore we decided to close his residual VSDs by device.

An LV angiography showed two moderate size residual VSDs, close to each other (Figure 1). The lower defect measured $5.5 \mathrm{~mm}$ and the distance from the upper edge of the lower defect to the upper edge of the upper defect was $8 \mathrm{~mm}$. A five $\mathrm{mm}$ Amplatzer ASD device (AGA Medical Co, Golden Valley, MN, USA) was deployed and released successfully at the lower defect hoping the left ventricular (LV) disc of the device will cover also the upper defect. A repeated RA pressure was $18 / 16 / 17 \mathrm{mmHg}$ and RV systolic pressure was $50 \mathrm{mmHg}$ with simultaneous LV systolic pressure of $90 \mathrm{mmHg}$. Therefore, the RV systolic pressure dropped from $80 \%$ of systemic pressure to $60 \%$ after the residual VSD closure. A control LV angiography shows small residual shunt through the upper VSD. At the end a pacemaker device with DDD mode was implanted.

The patient improved dramatically and discharged home within two weeks but on heavy medications. On follow-up he improved slowly, Echo continued to show moderate tricuspid valve regurgitation and the shunt jet through the upper small residual VSD is directed obviously from LV to RA. Thus, he was catheterized again, the Qp:Qs calculated to be $1.6: 1$ and the LV angiography showed a $1.7 \mathrm{~mm}$ residual VSD. A four mm Amplatzer muscular VSD (AGA Medical Co, Golden Valley, MN, USA) device was used to close the second residual defect. Control LV angiography showed complete closure (Figure 2).

At the control visit, one year after last catheterisation, he is active, in NYHA class I/VI, has no symptoms, his weight $17.5 \mathrm{~kg}$, and on small dose of diuretics.

\section{Case 4}

This is a four months old baby referred to us due to cardiac murmur and failure to thrive. On examination her weight was $4.2 \mathrm{~kg}$, tachypneoic, and fully saturated. On auscultation she had III/VI systolic murmur

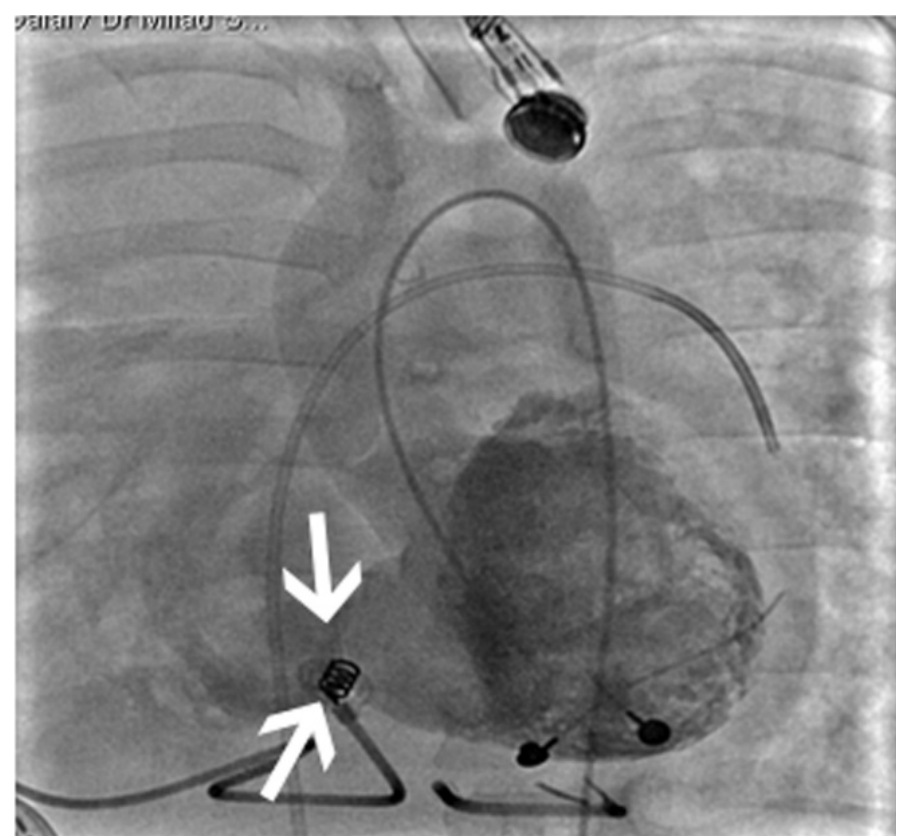

Figure 1. Left ventricle angiography shows two residual VSDs (arrows)

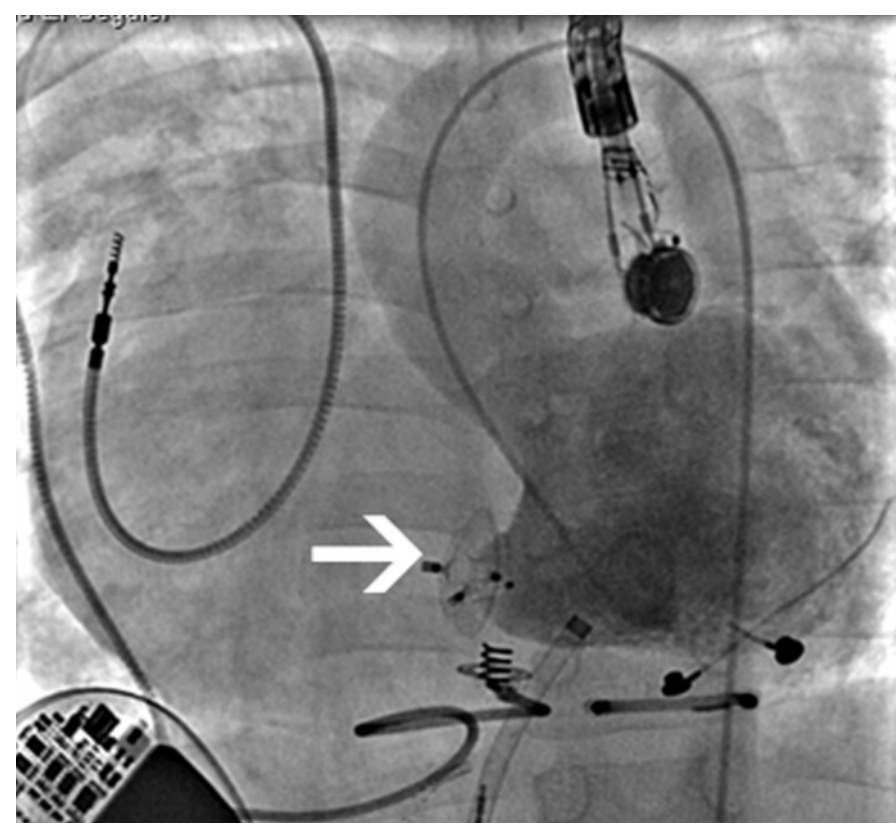

Figure 2. Left ventricle angiography shows complete closure of the residual VSD by devices. The devices (arrows) overlap each other.

over the pulmonary area, with some accentuation of the second heart sound. Echo showed moderate large atrial septal defect with left to right shunt, mild tricuspid regurgitation with maximum velocity of $4 \mathrm{~m} / \mathrm{sec}$, large midmuscular VSD $(8.5 \mathrm{~mm})$, depressed myocardial function (SF $25 \%$ ), volume loaded left atrium and left ventricle and normal coronary artery anatomy. The aortic arch anatomy was not clear by echo. The girl was catheterized, to evaluate the coronary arteries and aortic arch anatomies.

\section{Procedure}

Under general anaesthesia she was electively intubated. Through pressure gradient measurements and aortogram, aortic coarctation was excluded. An LV angiography was performed and showed a midmuscular VSD measuring $5.4 \times 8 \mathrm{~mm}$. The pulmonary artery pressure was $85 \%$ of systemic pressure with low diastolic pressure. The Qp/Qs was 2.8:1 and the PVRI was less than 2 WU. As the baby was sick with depressed myocardial function, we conclude that sending her to surgery might be very risky. Thus we decided (despite her low weight, $4.2 \mathrm{~kg}$ ) to close the VSD with an $8 \mathrm{~mm}$ muscular VSD device knowing that the procedure may carry certain risks, which was discussed in advance with the parents.

The arterio-venous loop was formed in the usual manner. As the VSD was below the moderator band, a curved course of the loop was accepted, i.e. a straight wire course of the catheter between the inferior vena cava and the ascending aorta could not be achieved. Because of this curved course, we decided to pass a 6 Fr long Amplatzer PDA delivery sheath from the venous access and position its tip within the LV cavity instead of the usual position in the ascending aorta, making sure not to interfere with the mitral valve chordae. An $8 \mathrm{~mm}$ Amplatzer muscular VSD device (AGA Medical Co, Golden Valley, MN, USA) was deployed successfully. By transthoracic echo an acceptable device form and position was confirmed. An LV control angiography before release of the device, showed some residual shunt. The device was released and by echo and fluoroscopy showed good position. The baby was extubated in the catheter laboratory and moved to the recovery unit. The day after, she showed clear clinical improvement through 
better appetite, more alert, less tachypnea and no signs of hemolysis. The chest X-ray showed decreased cardiac size, and the VSD device in good position. The ECG showed sinus rhythm and no sign of heart block. By echo the VSD device has stable position; the upper edge of the LV disc was impending slightly within the defect itself. There is mild to moderate residual left to right shunt and both ventricles had decreased in size and already showed better myocardial function (SF 38\%). On follow up 4, 7 and 12 months later she improved clinically very much, her weight increased to 6.2, 8.6 and $11 \mathrm{Kg}$ respectively. She had normal ECG and X-ray. The echo still showed tiny residual VDS, tiny ASD and normal myocardial function.

\section{Case 5}

This girl was referred to us at the age of 45 days with body weight of $2.3 \mathrm{~kg}$ and diagnosis of aortic arch hypoplasia and aortic coarctation as well as large VSD. She underwent surgical repair of the complex aortic coarctation. Clinically the baby remained critically sick with anuria; creatinine was $205 \mathrm{umol} / \mathrm{l}$ and urea $8.5 \mathrm{mmol} / \mathrm{L}$, albumin 22 $\mathrm{g} / \mathrm{L}$ and platelet count $30 \times 100 / \mathrm{uL}$. Two days postoperatively, she was deteriorated and had significant Doppler gradient across the middle aortic arch (between left carotid artery and left subclavian artery). We decided (on vital indication) to attempt careful balloon dilation of the anastomosis hoping to improve renal perfusion.

\section{Procedure}

At catheterization a small contrast volume was injected (keeping in mind poor renal function) at the ascending aorta which showed a stenotic segment between brachiocephalic artery and left carotid artery (Figure 3). The systolic Pressure gradient between ascending and descending aorta was $55 \mathrm{mmHg}$ with weak pulsatile flow in the descending aorta. The stenosed segment was balloon dilated using a $3 \mathrm{~mm} \times 12 \mathrm{~mm}$ Quantum PTCA balloon (Minesota USA). After dilatation the pressure in the descending aorta remained low and not pulsatile. At that stage larger balloons (first $4 \mathrm{~mm} \times 12 \mathrm{~mm}$ and later $5 \mathrm{~mm} \times 12 \mathrm{~mm}$ Quantum PTCA balloon) were utilized to dilate the stenoses. Because of the poor renal function, no control angiography was performed after the intervention. The descending aortic pressure became more pulsatile, though the gradient dropped from $55 \mathrm{mmHg}$ to $40 \mathrm{mmHg}$. Two days after the intervention the child improved clinically and improved kidney functions.

Unfortunately, one month later, she remained ventilator dependent and Doppler echo suggested a restenosis with a gradient of $50 \mathrm{mmHg}$. It was elected to take the baby back to the catheterization and balloon dilate the stenosed area. An angiography was performed which showed tight stenosis at the same segment $(2.2 \mathrm{~mm})$. The aortic size proximal to the stenosis was $4.5 \mathrm{~mm}$. Balloon dilation was performed using a $5 \mathrm{~mm}$ $\mathrm{x} 12 \mathrm{~mm}$ Quantum PTCA balloon. After the intervention the pressure gradient between the ascending aorta and the descending aorta was only $8 \mathrm{~mm}$ and the angiography showed improvement of the stenosed area (Figure 4).

Unfortunately, even with acceptable result of intervention to the re-coarctation the baby stayed to be ventilator dependent and $\mathrm{x}$-ray shows sign pulmonary over flow. Because of the condition of the baby and the body weight $(2.1 \mathrm{~kg})$, a complete repair was judged not feasible. One week later she was taken for palliation with $\mathrm{PAB}$ hoping it will lead to improvement of the status. Post PAB, the Doppler gradient indicated high pulmonary artery pressure. Hence, she was treated with Nitric Oxide for four days and the baby then gradually showed some improvement, which lead to wean off the inotropic support. Ten days postoperatively she had sepsis and was treated with antibiotics.

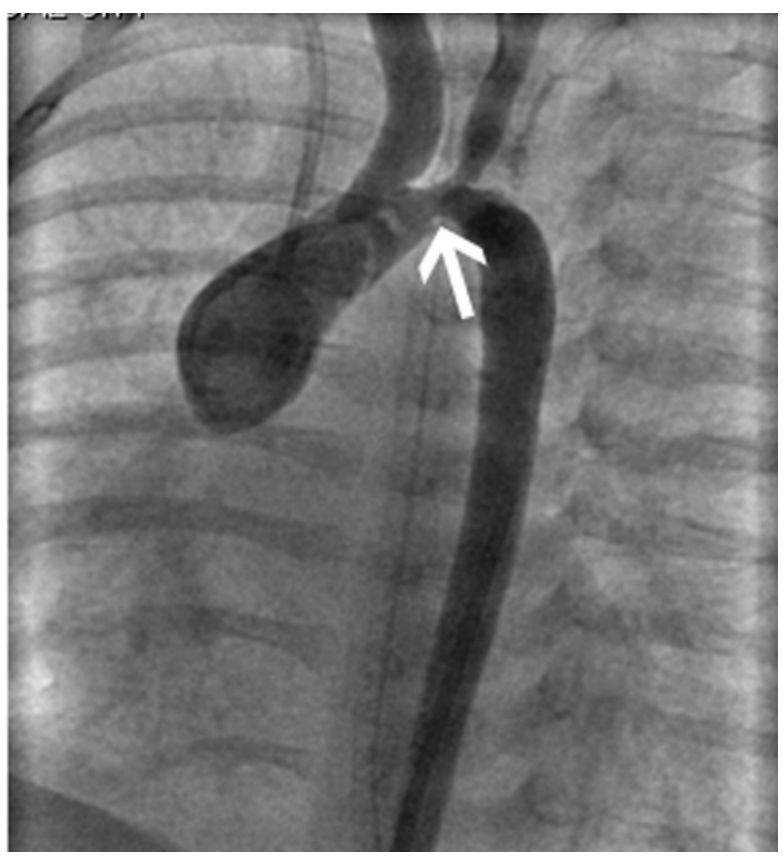

Figure 3. Angiography of aortic arch shows tight stenosis between brachiocephalic artery and left carotid artery (arrow). The left subclavean artery is not shown clearly because of small contrast volume

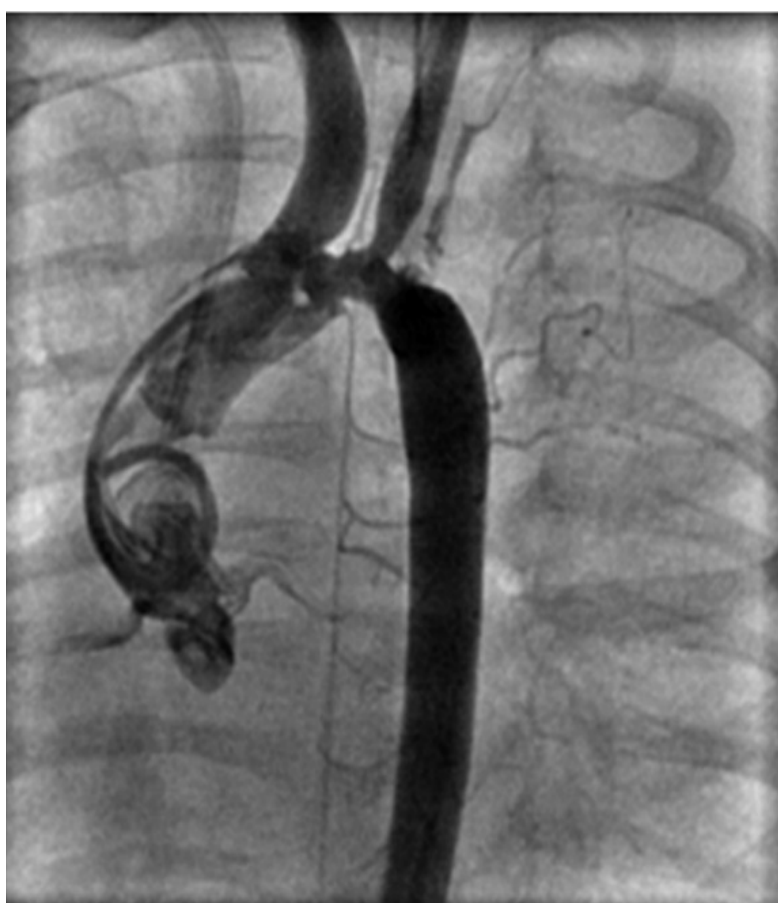

Figure 4. Angiography of aortic arch after balloon dilatation of the stenotic segment. The left subclavean artery is not shown clearly because of small contrast volume

Sixteen days after PAB, the baby suddenly deteriorated with hypoxia, hypotension and bradycardia. The cardio-pulmonary resuscitation started but unfortunately there was no response and the baby died.

\section{Case 6}

A boy born with situs ambiguous, single atrium, single ventricle, Transposition of the great arteries, bilateral superior vena cava, interrupted inferior vena cava with hemiazygos continuation to the 
left superior vena cava (LSVC) and hypoplasia of both pulmonary artery branches. At the age of one month, with saturation of $65-70 \%$, a four mm modified left Blalock-Taussig (BT) shunt was implanted. Postoperatively, he continued to have saturation above $80 \%$ and showed acceptable weight gain. At age of 14 months (weight $9.3 \mathrm{~kg}$ ) he underwent bilateral, bidirectional cavo-pulmonary (Glenn) shunt. Postoperatively, he remained ventilator dependent with very low saturation (35-60\%) and mild signs of superior vena cava syndrome. He was not acidotic and there is good peripheral perfusion. Initially we interpret his clinical picture due to elevated pulmonary artery pressure which may be caused by reactive pulmonary vasoconstriction. He was treated with pulmonary vasodilator (Sildinafil $2 \mathrm{mg} / \mathrm{kg} / \mathrm{dose}$ ) which lead to minimal improvement. Three weeks later he was taken to cardiac catheterisation to evaluate his hemodynamics and patency of Glenn anastomoses.

\section{Procedure}

After getting the vascular access, a catheter was advanced through the hemiazygos vein and LSVC, left pulmonary artery (LPA), right pulmonary artery (RPA) and retrograde into the right SVC. Mean pressure in RSVC, LSVC and hemiazygos vein was $28 \mathrm{mmHg}$. In the RPA and LPA was $23 \mathrm{mmHg}$. Angiographies were done at different areas to access the anatomy. There were significant stenoses at the right and left sided Glenn anastomoses as well as in the proximal LPA (both vessels $3 \mathrm{~mm}$ in size). We decided to a) balloon dilate the right sided Glenn anastomosis using a $6 \mathrm{~mm}, 2 \mathrm{~cm}$ Osypka balloon catheter (Koeln, Germany), b) stent the left sided Glenn with a $6 \mathrm{~mm} \times 15 \mathrm{~mm}$ hippocampus stent (Abbott, Illinois, USA), and c) stent the LPA stenosis with a $6 \mathrm{~mm}, 20 \mathrm{~mm}$ hippocampus stent (Abbott, Illinois, USA). The stents at the left Glenn anastomosis and LPA was deployed using the "kissing" technique. After deployment of the stents, hemodynamics was obtained and repeat angiographies showed improved flow across the previous stenotic areas.

Unfortunately, this management did not show immediate improvement in oxygen saturation, though the pressure gradient between the LSVC and the PA decreased significantly (from 5 to 2 $\mathrm{mmHg}$ ). The patient then started on Clopidogril $1 \mathrm{mg} / \mathrm{kg} /$ day and Acetyl Salicylic Acid 3mg/kg/day once daily as thrombosis prophylaxis. During the following days he improved slowly, and showed better saturations (75-80\%). Eventually (after two weeks) he could be extubated. The baby could be discharged home (five weeks after cardiac catheterisation) with good clinical status and saturation of $75-80 \%$. Latest follow up, ten months post procedure, patient was clinically well with weight of $14 \mathrm{~kg}$ and saturation $85-88 \%$ on room air.

\section{Discussion}

\section{Accepted guidelines for care}

There are accepted guidelines for standard of care which have been adopted over the years and found to be useful for the different congenital heart disease (CHD). In the industrialized countries, where most of these standards of care were developed and implemented, the advanced and well-structured health care delivery helped to evaluate these management strategies [4,5]. In contrast, in many developing countries, the health care level does not always support to implement these recommendations [6].

\section{Situation leading to applying tailored approach}

In these countries, often the concept of primary health care physician is not yet well institutionalized. Additionally, there are often not enough beds in tertiary care hospitals to accommodate all needy sick patients, from the start. Thus, many patients with treatable CHD may remain in peripheral hospitals -occasionally ventilated- for long times with suboptimal management and arrive late to the tertiary care centres [7]. Other patients are treated for weeks assuming a diagnosis which later turns out to be incomplete or incorrect. Additionally, the general and nutritional status may become very poor which may further complicate the situation and affect negatively the outcome of any planned operative management [8].

\section{Our observation}

All these reasons, among others, made it occasionally difficult to treat patients according to acknowledged standard of care, despite presence of well trained and experienced physicians in the tertiary care centers. We noticed that when following the recommended guidelines in these critically sick children they often either had major postoperative morbidities, struggled with postoperative extubation, multiple infections, multiorgan failure etc) or even died. As they otherwise had surgically treatable CHD, we thought that the associated impaired cardiac function, long term ventilator dependency or chronic lung disease may carry extremely high risk [9]. Therefore, we believed that preoperatively the general clinical status and myocardial condition need to be optimized. It has been shown that they do influence the results of paediatric open cardiac surgery [10]. Hence, a tailored and individualized approach was developed for every one of these patients.

\section{Impact of therapeutic cardiac catheterization on management of CHD}

The advancement in the less invasive paediatric therapeutic catheterization procedures helped to develop and implement some tailored approaches, which allowed preparing the patients to postpone and later undergo the necessary but more invasive cardiac surgery with potentially lower risk [11].

In the current paper we reported cases with $\mathrm{CHD}$ which were referred to our institute for surgical treatment. However, at their arrival were either late presenter, or critically sick with suboptimal treatment. Some were marasmic, with chronic lung disease, and some even ventilator dependent for long time. We chose to treat these patients with a tailored approach instead of a one stage surgical repair. We started with optimizing their medications and nutrition. Then we offered them partial treatment, utilizing interventional procedures in the cardiac catheterisation laboratory. It was preferred to give them some time to further improve their general and cardiac status. Finally, the patient was sent to the originally planned major cardiac surgery. At least this approach improved the general clinical condition of our patients and possibly it was the reason behind minimizing the assumed higher risk of the final cardiac surgery and probably avoiding poor final outcome.

Though Jenkins KJ et. al. (2001) discussed the risk stratification according to diagnosis and many other parameters; however, the preoperative nutritional status was not included. Which we believe it is of significant importance at least in the patient category we presented.

\section{Changes needed in the health care system to avoid having such patients}

In many developing countries there is a clear trend to invest more in health care delivery. This is also obvious in paediatric cardiac institutes, though for many of these countries this very expensive specialization does not represent one of the most pressing needs of the population. 
Due to many reasons, there are not enough bed facilities to accommodate patients with CHD. Furthermore, as mentioned before, the concept of the primary health care physician was not yet implemented.

As prophylaxis is often much better than treatment, it is worth thinking about how to reduce the existence of such patient category, who remain at risk to have poor prognosis, despite our conservative treatment approaches. It is our understanding that one of the possibly most important ways to improve the service of these patients and others is to improve and invest on the concept of primary health care. Doing this, as has been shown elsewhere, will alert the parents that their children need urgent attention by a specialist. Other issues would be to improve in the vaccination program offered to this community, especially in regard to the RSV, which has been shown that it can have a deleterious effect on infants with congenital heart disease [12].

\section{Pro and con tailored approach}

Though we are promoting this concept in selected cases, we are also aware that therapeutic catheterization in low weight infants do have their difficulties and occasionally serious complications. Examples for these complications are the vascular access sites, the need for TEE, the excessive radiation risk, potential arrhythmia during the procedure and cardiac perforation [13]. However, in skilled hands, planned procedure with improvement and miniaturization of the instruments used, reduced the expected complications significantly [14]. In our patient we did not experience any complication.

In order to proof that our approach is safer than proceeding with one stage surgical approach, a controlled randomized study would be warranted. Such a "scientific" approach would be unethical, as it is common sense that patients in marasmic status or ventilator dependent must have higher risk of dying than well-nourished and non-ventilator dependent patients even after successful surgical procedure.

\section{Conclusion}

Putting all this in mind, we believe there is no easy way out of this dilemma. We know that occasionally in medicine, common sense drives our management. In our case the advancement of interventional therapeutic procedures helped to tailor management of these unfortunate patients.

\section{References}

1. Hijazi ZM, Awad SM (2008) Pediatric cardiac interventions. JACC Cardiovascular interventions 1: 603-611. [Crossref]

2. Bacha EA, Hijazi ZM (2005) Hybrid procedures in pediatric cardiac surgery. Semin Thorac Cardiovasc Surg Pediatr Card Surg Annu 78-85. [Crossref]

3. Smith P (2001) Primary care in children with congenital heart disease. J Pediatr Nurs 16: 308-319. [Crossref]

4. Feltes TF, Bacha E, Beekman RH, Cheatham JP, Feinstein JA, et al. (2011) Indications for cardiac catheterization and intervention in pediatric cardiac disease: a scientific statement from the American Heart Association. Circulation 123: 2607-2652. [Crossref]

5. Mahle WT, Newburger JW, Matherne GP, Smith FC, Hoke TR, et al. (2009) Role of pulse oximetry in examining newborns for congenital heart disease: a scientific statement from the American Heart Association and American Academy of Pediatrics. Circulation 120: 447-458.

6. Saxena A (2009) Congenital cardiac surgery in the less privileged regions of the world Expert Rev Cardiovasc Ther 7: 1621-1629. [Crossref]

7. Geggel RL (2004) Conditions leading to pediatric cardiology consultation in a tertiary academic hospital. Pediatrics 114: e409-417. [Crossref]

8. Cameron JW, Rosenthal A, Olson AD (1995) Malnutrition in hospitalized children with congenital heart disease. Arch Pediatr Adolesc Med 149: 1098-1102. [Crossref]

9. Brown KL, Ridout DA, Hoskote A, Verhulst L, Ricci M, et al. (2006) Delayed diagnosis of congenital heart disease worsens preoperative condition and outcome of surgery in neonates. Heart 92: 1298-1302. [Crossref]

10. Clancy RR, McGaurn SA, Wernovsky G, Spray TL, Norwood WI, et al. (2000) Preoperative risk-of-death prediction model in heart surgery with deep hypothermic circulatory arrest in the neonate. J Thorac Cardiovasc Surg 119: 347-357. [Crossref]

11. Allen HD, Beekman RH, Garson A Jr, Hijazi ZM, Mullins C, et al. (1998) Pediatric therapeutic cardiac catheterization: a statement for healthcare professionals from the Council on Cardiovascular Disease in the Young, American Heart Association. Circulation 97: 609-625. [Crossref]

12. Feltes TF, Cabalka AK, Meissner HC, Piazza FM, Carlin DA, et al. (2003) Palivizumab prophylaxis reduces hospitalization due to respiratory syncytial virus in young children with hemodynamically significant congenital heart disease. The Journal of pediatrics 143: 532-540. [Crossref]

13. Stanger P, Heymann MA, Tarnoff H, Hoffman JI, Rudolph AM (1974) Complications of cardiac catheterization of neonates, infants, and children. A three-year study. Circulation 50: 595-608. [Crossref]

14. Venkataraman ST, Thompson AE, Orr RA (1997) Femoral vascular catheterization in critically ill infants and children. Clin Pediatr (Phila) 36: 311-319. [Crossref]

Copyright: (C2017 El-Segaier M. This is an open-access article distributed under the terms of the Creative Commons Attribution License, which permits unrestricted use, distribution, and reproduction in any medium, provided the original author and source are credited. 